\title{
World Landslide Forum \\ Delineation of Endangered Areas in a slowly moving landslide by the Pressure Probe method \\ --Manuscript Draft--
}

\begin{tabular}{|c|c|}
\hline Manuscript Number: & WLFO-D-16-00007R1 \\
\hline Section/Category: & Vol. 2 - Session 4 - Landslide Hazard, Risk Assessment \& Prediction \\
\hline Abstract: & $\begin{array}{l}\text { Mechanically weak zones which may not visible from the surface and which may occur } \\
\text { e.g. due to landslides can be detected and characterized by the newly developed } \\
\text { Pressure Probe (Pre-P)method. On a high bank at Dunaszekcsö, Hungary, the fracture } \\
\text { system of the loess landslide area was investigated by large resolution applying this } \\
\text { method and proved that: } 1 \text {. cracks as small as } 2-3 \mathrm{~cm} \text { wide are detectable; } 2 \text {. The } \\
\text { fractures follow each other almost periodically; } 3 \text {. On the side of the fractures towards } \\
\text { the slump there are less fractured zones whose width correlates with the width of the } \\
\text { given fracture. We also demonstrated that on the passive side of the clearly visible } \\
\text { fracture: } 1 \text {. There are also fractures along which future rock displacement is expected; } \\
2 \text {. These fractures are at least as wide as the active side fractures; } 3 \text {. The blocks there } \\
\text { are about twice as wide as those on the active side. A block several meters wide is } \\
\text { expected to fall before the main mass movement. The Pre-P method seems to be the } \\
\text { most powerful tool to map the fracture system of such landslides because of its speed, } \\
\text { simplicity of application, cost and interpretation. The Pre-P profiles and maps of the } \\
\text { fracture system of a landslide enable to understand landslide evolution and delineate } \\
\text { endangered areas earlier than by other methods. }\end{array}$ \\
\hline Corresponding Author: & $\begin{array}{l}\text { Sándor Szalai } \\
\text { MTA CSFK GGI } \\
\text { HUNGARY }\end{array}$ \\
\hline \multicolumn{2}{|l|}{$\begin{array}{l}\text { Corresponding Author Secondary } \\
\text { Information: }\end{array}$} \\
\hline \multicolumn{2}{|l|}{ First Author Secondary Information: } \\
\hline \multirow[t]{3}{*}{ Order of Authors: } & Sándor Szalai \\
\hline & Viktor Wesztergom \\
\hline & Kitti Szokoli \\
\hline \multicolumn{2}{|c|}{ Order of Authors Secondary Information: } \\
\hline Author Comments: & - \\
\hline Response to Reviewers: & $\begin{array}{l}\text { Dear Reviewers, } \\
\text { The full paper is now uploaded. } \\
\text { Thanks for your work. } \\
\text { Yours sincerelly, } \\
\text { Sándor Szalai }\end{array}$ \\
\hline
\end{tabular}




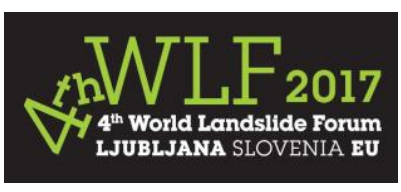

Sándor Szalai ${ }^{(1)}$, Viktor Wesztergom ${ }^{(1)}$ and Kitti Szokoli(1)

\title{
Delineation of Endangered Areas in a slowly
} moving landslide by the Pressure Probe method

\begin{abstract}
Mechanically weak zones which may not visible from the surface and which may occur e.g. due to landslides can be detected and characterized by the newly developed Pressure Probe (Pre-P) method. On a high bank at Dunaszekcső, Hungary, the fracture system of the loess landslide area was investigated by large resolution applying this method and proved that: 1 . cracks as small as $2-3 \mathrm{~cm}$ wide are detectable; 2 . The fractures follow each other almost periodically; 3 . On the side of the fractures towards the slump there are less fractured zones whose width correlates with the width of the given fracture. We also demonstrated that on the passive side of the clearly visible fracture: 1. There are also fractures along which future rock displacement is expected; 2. These fractures are at least as wide as the active side fractures; 3 . The blocks there are about twice as wide as those on the active side. A block several meters wide is expected to fall before the main mass movement. The Pre-P method seems to be the most powerful tool to map the fracture system of such landslides because of its speed, simplicity of application, cost and interpretation. The Pre-P profiles and maps of the fracture system of a landslide enable to understand landslide evolution and delineate endangered areas earlier than by other methods.
\end{abstract}

Keywords

loess, slowly moving landslide, Pressure Probe method, fracture system

\section{Introduction}

Landslides are an increasing danger to human life and constructions with the increasing population and climate changes which induces heavy rains. It is therefore important to map landslide endangered areas, diagnose their risk and monitor them. To fulfil these requirements, the geophysical methods can be very useful. The goal of the geophysical techniques used to be almost exclusively the horizontal and/or vertical delineation of the sliding mass. The inner structure of the landslide or the characterisation of the eventually existing sliding surface was studied less often.

Geotechnical methods can be used to get information on sediment stratification and soil type, to detect quick clay and to verify bedrock depth. Laboratory tests on material from core samples give detailed information on sediment stratification, soil type, shear strength, deformation properties, and permeability, etc.

Remote sensing techniques are also very valuable tools in landslide investigations. Mapping the surface area affected by landslide is often done by observation of aerial photographs or remote sensing images (Van Westen, 2004) which indicate the topographical expression of the landslide. However, if the landslide is ancient or inactive, its morphologic features and boundaries may have been degraded by erosion and surface observations and measurements have to be supported by reconnaissance at depth (Dikau et al., 1996). Geodetical methods are also distributed in landslide investigations as shown by Újvári et al. (2009) and Bányai et al. (2013).

All of these techniques were mostly used in the investigation of landslides where the moving material differed from the remaining material. In our case the slump arose in a homogeneous rock mass. The physical properties of the area endangered by landslides are not different from the stable area so it cannot be delineated by geophysical tools. In this case the description of the sliding surface may still be useful because it determines the area which is going to move. Independent of the existence of any sliding surface, it is also possible to 
describe the fracture system which enables the delineation of the endangered area. If the fractures are visible on the surface, they can directly help in the delineation. However if they are not observable, they have to be detected using geodetic, geotechnical or geophysical methods. Geophysics has not been effective in this case but if the characteristic distance of the fractures were much larger, (about $10 \mathrm{~m}$ ), Electric Resistivity Tomography was able to detect fractures (Francese et al 2009). The other possibility is to use geoelectric null-arrays (Szalai, Szarka, 20o8; Falco et al., 2013). Geoelectric arrays can also be useful in determining fracture directions (Taylor and Fleming, 1988), but within strict limits (Szalai et al., 2009).

Barnhardt and Kayen (200o) detected fractures by GPR, but the resolution of their measurements was only $5 \mathrm{~m}$. The geotechnical tools which are theoretically useful in mapping fractures are expensive and their use is strongly limited by field conditions, like topography, artificial constructions, mass movement danger and vegetation, which limit or prevent access by vehicles which are necessary to carry out such measurements.

For these reasons we decided to use a method which avoids such problems and is fast, cheap and effective. The Pre-P method is just a simplified version of the CPT technique. The Pre-P method measures only the mechanical resistivity of the soil at shallow depths. This method is well applicable because most of the fractures reach close to the surface but they are not visible due to the vegetation cover and the soil eroded into them and fixed by roots. When crossing the roots of plants, the Pre-P instrument is able to detect fractures due to their decreased mechanical resistance. The investigation which was carried out using this principle will be presented later in more detail. As a result, it is possible to map the fracture system of the study area making possible the delineation of the endangered area in time.

\section{Geological and geomorphological settings}

The study area (Fig. 1a) belongs to the Baranya Hills in South Hungary (Fig. 1b). Figure 1a presents the site where the measurements have been carried out and the measuring profiles, Figure ic shows the plan view of the area with the profiles.

The Triassic-Jurassic limestone formations at Dunaszekcső are located at 200-250 $\mathrm{m}$ below the surface (Moyzes and Scheuer, 1978). These basement rocks are covered by clayey and sandy sediments that can be found below about 70m depth under the southern moving block (SB) according to borehole data. The uppermost $70 \mathrm{~m}$ of the sediment sequence at SB are sandy and clayey loess layers with brown to red fossil soils accumulated during the Pleistocene (Fig. 2). The bluff reaches its highest point (142 $\mathrm{m}$ a.s.l.) at Vár
Hill where the southern part of the moving blocks is located. The flood plain of the Danube is very narrow or missing below SB at Vár Hill. The bluff consists of a 20$30 \mathrm{~m}$ high vertical loess wall above the $10-20 \mathrm{~m}$ high slopes that consist of reworked loess from past landslides and fluvial mud, sand and gravel deposits of the Danube (Fig. 2).

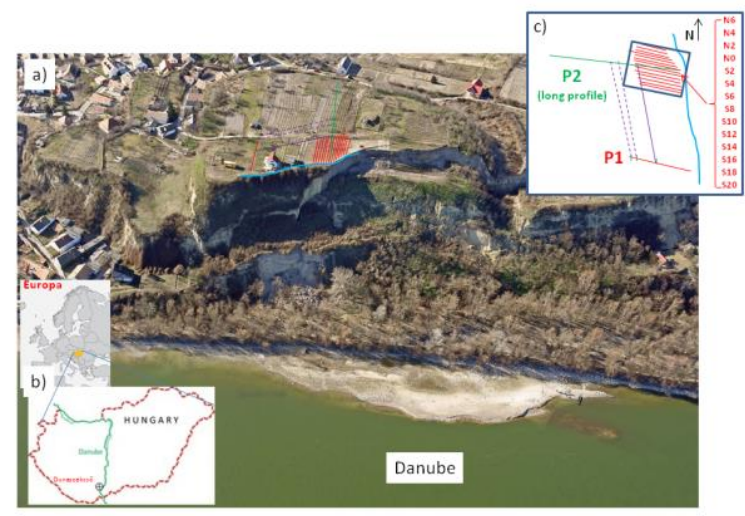

Fig. 1 a. Aerial photograph of the landslide site with the study area and the Pre-P profiles. b. Location of the study area. c. Plan-view of the study area with the Pre-P profiles (red and green solid lines). Supposed major fractures outside of the active area on the basis of the $\mathrm{P}_{1}$ and $\mathrm{P}_{2}$ profiles (lila lines). Numbers denote the shorter profiles from north to south. Blue curve displays the actual scarp. The rectangle illustrates the area where the map of Fig. 7 was made.

Field observations show the development of tension cracks in the loess complex parallel as well as perpendicular to the channel of the Danube, indicating reduced rock strength. The vertical cracks are clearly visible on the roof of the Töröklyuk cave, a large natural cavity on NB.

One of the most important factors of landsliding is the hydrological condition of high bluffs. The Danube has a water level fluctuation in a range of nearly $10 \mathrm{~m}$ that influences the springs of ground and artesian water at the foot of the bank, which is inundated during higher water stages but experiences rapid draining during lower water stages. It is supposed that this water level fluctuation leads to lack of mass throught chemical processes in large depth. This lack of mass results in slumping of the overlying deposits, which means that sliding surface does not exist in its common sense.

Along the steep bank of the Danube, the Upper Pannonian sediment sequence consisting of alternating permeable and impervious layers is exposed in some 
places below the Pleistocene or Upper Pliocene loess sequence or the Pliocene red clays.

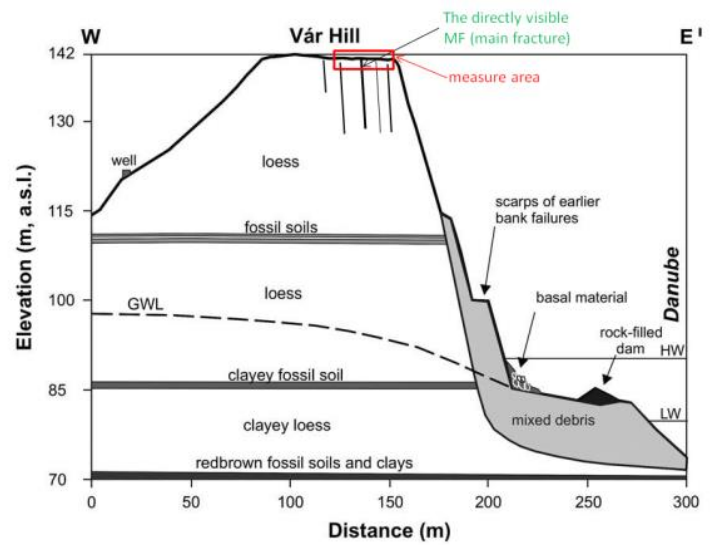

Fig. 2 Geological cross-section of the high bank at Dunaszekcső (modified after Moyzes and Scheuer, 1978; Pécsi et al., 1979; Kraft, 2005). Elevation and distance were derived from the digital terrain model which was provided by geodetic measurements of 433 points. Vertical exaggeration: $\times 3 . \mathrm{GWL}=$ ground water level (in July 2008); HW=highest water; LW=lowest water. The measure area is shown by the rectangle.

A more detailed geologic description and former researches which have been carried out in the study area are given in Újvári et al. (2009). Figure 3 presents some photos about the area: the loess mass which has already slumped (Fig. 3a), the quasi vertical scarp (Fig. $3 \mathrm{~b})$, the study area from western direction with tapes along profiles $\mathrm{S}_{4}$-Sio (Fig. 3c) and the main fracture from the east with profiles $\mathrm{S}_{4-10}$ (Fig. 3d).

\section{The Pressure-probe (Pre-P) method}

We used a simplified penetrometer shown in figure $4 \mathrm{a}$; the sketch of the measurement is displayed in figure 4b. The fractures of the study area are often hidden by vegetation and soil (Fig 4c). The plants themselves can also be good indicators of fractures due to e.g. their different colours in the micro-valleys sometimes arising along fractures. However, other tools are often required to map fractures. Therefore the Pre-P method using the deeper penetration of the penetrometer at the locations of fractures proved to be one of the most useful tools for this aim.
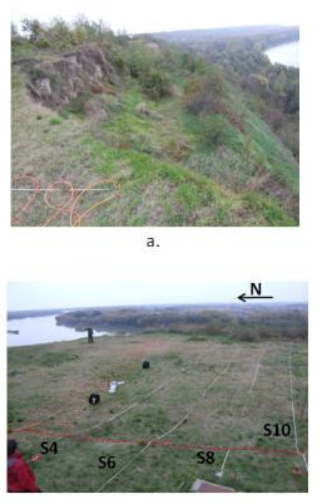

c.

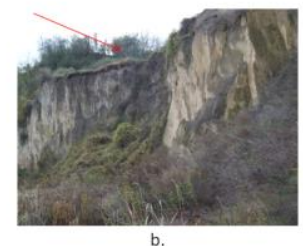

b.

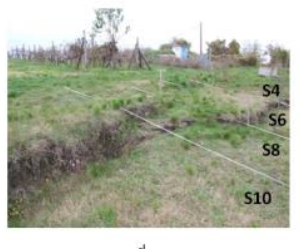

Fig. 3 a. The loess mass which has already slumped looking from the south, (the direction of the study area.) b. The quasi vertical scarp. The arrow indicates the research area. c. The study area from western direction with tapes along profiles $\mathrm{S}_{4}$-Sio. The profiles are closely West-East orientated. The dotted red line shows the main fracture which is directly visible from the opposite direction. $\mathrm{d}$. The main fracture from the east with profiles $\mathrm{S}_{4}$-10. The long profile $\left(\mathrm{P}_{2}\right)$ elongated between two vineyards in line Sio.

Our tool is a metal rod on which a metal disc is fixed to increase its weight (Fig. 4a). One lets it fall down from a height of $1 \mathrm{~m}$ as perpendicular as possible (Fig. 4c). This height was marked on the clothes of the crew members to hold it throughout the measuring process. The maximum measurable penetration depth was 30 $\mathrm{cm}$ which proved to be perfect in the study area. The measuring instrument sank deeper only in very wide fractures. In such locations $30 \mathrm{~cm}$ was noted which made possible to present the values here without distorting the profiles/maps by extremely large values.

The metal disc also prevented the tool from falling into visible or hidden fractures. The detailed description of the Pre-P instrument is in Appendix A. The Pre-P instrument was constructed to penetrate to a wide interval of depths to get the most possible information under field conditions. The tool proved to be perfect for this aim. It generally sank between 7 and $15 \mathrm{~cm}$ and larger values occurred only at fractures. In the future similar measurements are planned to be done using a penetrometer to locate the measuring points more precisely. In this way measurements could be carried out with smaller sampling distances. 


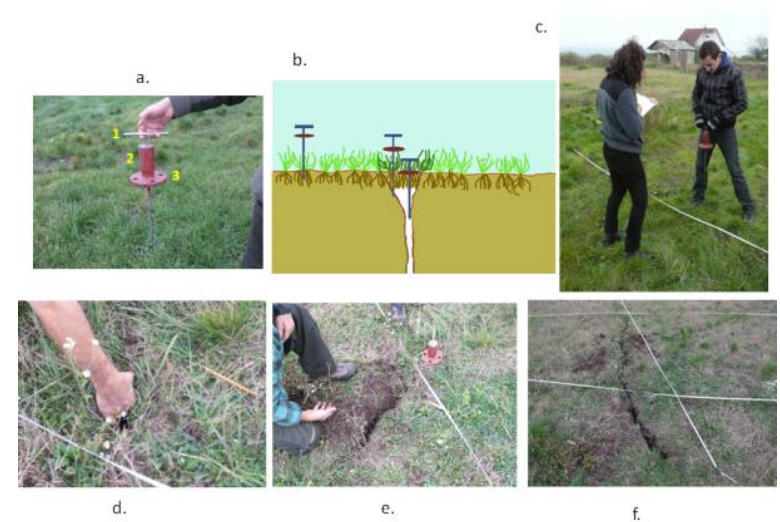

Fig. 4 The measurement process; a. The instrument; 1. T-shaped metal rod; 2 . upper weight; 3 . lower weight; b. Measurement and data registration; c. Plan of the Pre-P method; d. Exploration of the crack detected by the Pre-P method and removal of vegetation from the suspected crack location; e. A partially explored crack; f. Part of the crack which has been explored (No. II, see Figure 8 below).

\section{Execution of the measurement}

The measurements were carried out on parallel profiles to map the fracture system of the study area. The distance of the profiles was $2 \mathrm{~m}$ and the sampling distance was $10 \mathrm{~cm}$. The direction of the profiles was quasi perpendicular to the supposed direction of the most interesting fractures which are nearly parallel to the edge of the hill. Generally only the penetration depth of the probe was recorded but if the value was remarkably different from the surrounding ones, the environment of the given point was investigated in more detail. It was done by thrusting a metal rod around the given position looking for mechanically weak zones. If zones were found which seemed to be connected to the one in the profile, the vegetation was removed by a metal rod. If a fracture was found there, it was followed for a distance (Fig 4d) by removing the vegetation along the fracture by hand and/or by a metal rod (Fig. 4d). Several fractures were found in this way (Fig. 4e) and many of them were excavated for longer distances (Fig. 4f).

\section{Results and interpretation}

\section{5a. Profiling}

The map of the study area with profiles N6-S2O is presented in figure 1c. Before interpreting it, we are going to interpret several profiles individually.

Significant, wide fractures were interpreted where the Pre-P values were much larger than in the neighbouring points. Outstanding values sometimes occurred only at one single measuring point but more often at several neighbouring points (Figs. 5 and 6).

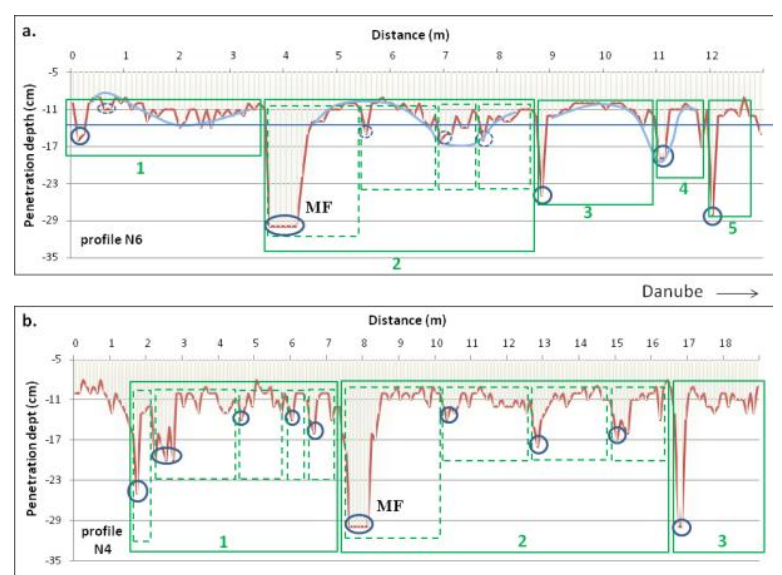

Fig. 5 Profiles N6 and N8. MF: main fracture

Zones were assigned to all dominant fractures. These are the zones which are on their eastern side and elongate from the given dominant fracture to the next dominant one. These zones were delineated by continuous line rectangles and numbered (see Fig. 5). These main fracture zones were further divided into smaller zones which belong to moderately significant, thinner fractures. These sub-zones were delineated by dotted line rectangles. The background values (where there are no fractures) were characteristically under 13 $\mathrm{cm}$, mostly in the range of $11-13 \mathrm{~cm}$. Higher values most likely refer to the presence of fractures. The narrow range of the background values verifies both the homogeneity of the loess and the robustness of the PreP method.

At first a few typical profiles are presented and interpreted. They were measured in the area which has already started to slump, that is eastward from the main fracture (MF, see in Fig. 3d) and which is directly visible. It is $20-80 \mathrm{~cm}$ wide and the vertical displacement along it is in the range of $10-70 \mathrm{~cm}$. Five prominent anomalies are clearly recognisable on profile N6 (Fig. 5a.). They are most likely linked to major cracks. There is only one much smaller crack of $0.3 \mathrm{~m}$ west of the MF at $3.6-4.2 \mathrm{~m}$. It is easily recognisable producing a strong local anomaly.

East of the MF approaching to the edge, the cracks follow each other ever more frequently. It can also be seen that on both sides of the fractures there are mechanically consolidated, stable zones and that they are wider in the active, eastern side than in the passive, western one. A possible reason of the stability of these zones is that the tension which is nearly the same everywhere before the mass movement is going to be much weaker in the displaced blocks after it thanks to their separation which resolves the largest part of this 
tension. Between the cracks the mechanical resistance of the soil seems to follow a nearly sinusoidal distribution (marked by a blue line). The wider a crack, the wider is the consolidated zone on its eastern side. One should mention that small Pre-P values (usually below $11 \mathrm{~cm}$ ) observed in the left end of the profile, are due to vehicles. The situation is the same for most of our profiles because they started in the path compressed by vehicles.

Although profile $\mathrm{N}_{4}$ (Fig. $5 \mathrm{~b}$ ) is just two meters away from profile N6 - only three remarkable zones can be seen. The first two can be divided into numbers of subzones. The large anomaly at $16.7 \mathrm{~m}$ suggests a mass fall along the surface perpendicular to the profile before the main slump along the MF (around $8 \mathrm{~m}$ ).

There are many small cracks on profile S6 (Fig. 6a), east of the MF at about $5 \mathrm{~m}$. It can be clearly seen that fracture zones 2-5 east of MF are narrowing towards the Danube River. Thinner cracks (in the left sides of the dotted rectangles) are present every 1-2 meters. This distance is in very good correlation with those observed in the cave at Töröklyuk which is close to the measuring area (Újvári et al, 2009). A rock fall can happen anytime on profile $\mathrm{S} 6$ at about $0.7 \mathrm{~m}$.

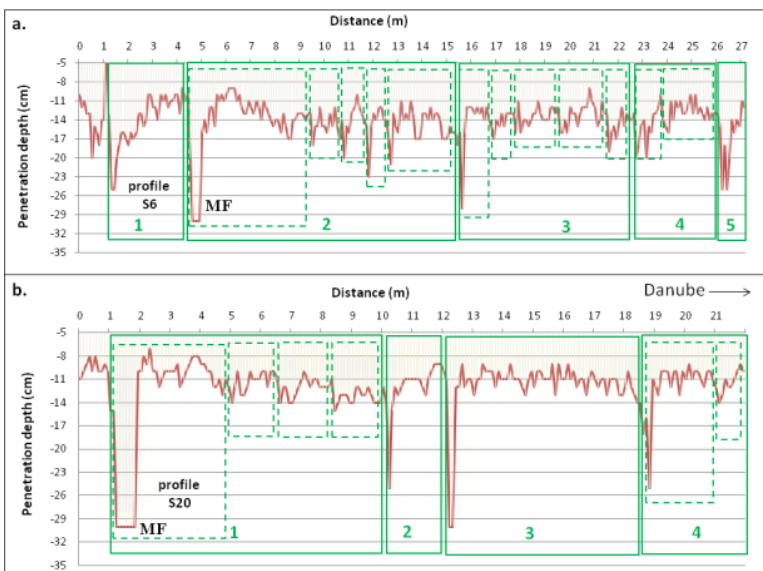

Fig. 6 Profiles S6 and S8. MF: main fracture

On the southernmost profile of the area (S2O, Fig. $6 \mathrm{~b})$, four fracture zones can be recognised. The stability of the first and especially that of the third zone where there are actually only minor cracks is interesting. There is a weekend house in this stable zone to the south, about $10 \mathrm{~m}$ from the profile. Its walls are not yet cracked, which supports our Pre-P results.

The above examples illustrate that with an appropriate sampling distance (which was $10 \mathrm{~cm}$ ) the $\mathrm{Pr}-\mathrm{P}$ method is able to detect and localise cracks (at least in areas similar to the one we investigated), as well as to estimate their width.

\section{5b. Mapping}

The $\mathrm{Pr}-\mathrm{P}$ map is presented in figure 7 . Beside of the fractures observable on the surface and marked by continuous yellow lines, numerous other fractures are clearly interpreted from the map. Such fractures are marked by yellow or purple dotted lines according to whether their direction is quasi-parallel or perpendicular to the hill edge. The width of the lines correlates with the supposed width of the cracks. There are two nearly perpendicular (XI-XII) fractures in the active area 10, to the edge parallel (I-X). The delineation of the compacted zones where the soil has a high mechanical resistance (marked by Arabic numerals) played an important role in marking the cracks.

On the basis of this map, a rock fall is expected along cracks VII and VIII before slumping along the MF.

The nearly parallel fractures are about 1-1.5 m from each other near the edge (o-12 $\mathrm{m}$ on the $x$ axis), and about 3-4 $\mathrm{m}$ farther from the edge $(12-21 \mathrm{~m}$ on the $x$ axis) with the exception of stable zones, especially area 3c.

Reinforcing the Pre-P results, some cracks were shorter or longer exposed which is discussed in section "The construction of measurement".

The longest fracture we explored is drawn by wide black dashed lines in figure 7. Although its trace coincides mainly with fracture II both in the southern and the northern part of the map, the trace diverged from it and merged into other supposed cracks. It is most likely due to transverse cracks which "diverted" the trace from the "principal" direction of the area. At the branching points only one crack was followed from all the possible fractures. Although fracture II is typically not wider than $5 \mathrm{~cm}$, it is clearly shown on the map, showing the effectiveness of the Pr-P method. It was able to detect even much thinner cracks than the sampling distance. If the profiles were taken closer to each other, one could get an even better image of the fracture system.

Delineation of stable zones can strongly support drawing the cracks. These stable zones always appear on the active side of the fractures (Fig. 7) in both larger dimensions (e.g. $3 a, b, c$ and $d$ zones which belong to the MF), and also in smaller dimensions (e.g. zone 5 in front of fracture II).

In our measurements we focused on the cracks which are quasi-parallel to the wall since they are decisive in terms of slumping. This is why the measurements were carried out perpendicular to the wall. Therefore the sampling distance was much smaller in this direction than parallel to the wall. Cracks perpendicular to the wall could be mapped in more detail, using the appropriate measuring direction. 


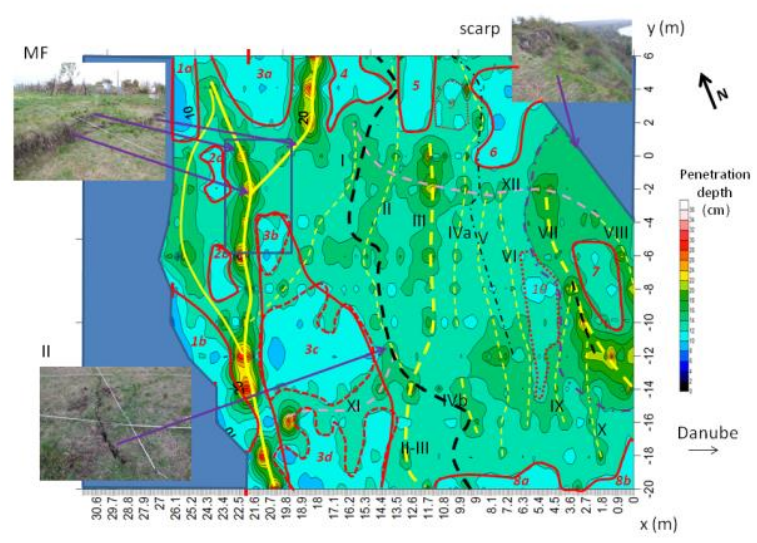

Fig. 7 The Pre-P map which was made using the results of the short profiles N6-S2o (see Fig ra and c). Solid yellow line marks the crack which is directly visible. Dashed yellow line: supposed cracks almost parallel to the scarp on the basis of the map. Dashed purple lines: supposed cracks almost perpendicular to the scarp on the basis of the Pre-P map. Dashed black lines marking the explored crack. Dotted black curve: partially excavated cracks. Arabic numerals indicate stable areas, Roman numbers the supposed cracks. The photos show the corresponding places indicated by arrows.

Overall assessment of the map provides the following conclusions: 1. The Pre-P method is appropriate to map the fracture system of an area; 2 . In the area we studied, many cracks were observed almost parallel to the edge whose distance is around 1-2 $\mathrm{m}$. The existence of several cracks was confirmed by exploring them. 3. Due to the sampling direction, cracks perpendicular to the wall could not have been detected in detail. 4. Along cracks No. VII and VIII, mass movement may happen anytime, even before the slumping along the MF. 5 . In order to get a better image, profiles should be taken closer to each other. A $1 \mathrm{~m}$ offset seems to be a good compromise between the effectiveness of measurement and the required investment.

\section{5c. Investigating of the area that is not yet endangered}

The main objective of the present study was to prove whether the Pre-P method is suitable for mapping the fissure system of an area and also to delineate the landslide endangered areas. The delineation seemed impossible because most of the area beyond the MF was cultivated, which prevents the use of the Pre-P method. For this reason, measurements were performed only along two profiles, which proved to be very informative. The most likely reason is that the cultivation of this area finished a long time ago.

Figure 8 displays the running average each of 3 consecutive values measured on profile P1 (Fig. 1c).
(Such averaging enables simpler interpretation, but it can lead to information loss which has to be therefore controlled). It is clearly seen that the area, which is located on the stable, not-sliding, passive side (o-49 m) from the MF is also fractured. The cracks in this zone have greater amplitude than on the active side (49-72 $\mathrm{m})$. The fragmentation of the loess appears to have been also started here. It is not surprising considering the dimensions of the Castle Hill: the height of the hill above the level of the Danube River is about $50 \mathrm{~m}$ while it is approximately $90 \mathrm{~m}$ long in the direction perpendicular to the riverbed (see Fig 2). It is worth mentioning that on the passive side of the MF there are 3 blocks, about $10 \mathrm{~m}$ wide (o-10 $\mathrm{m}, 23-34 \mathrm{~m}, 38-48 \mathrm{~m}$ ). On the active side the blocks are only about 3-6 m wide. There are only two cases of penetration values below $13 \mathrm{~cm}$ : the anomaly at $43-45 \mathrm{~m}$ shows both wheel tracks which are definitely recognizable. The reason for the anomaly at about $21 \mathrm{~m}$ is unknown.

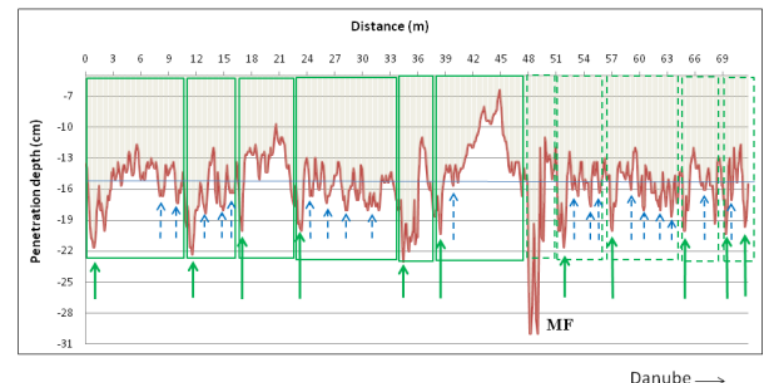

Fig. 8 Pre-P results on Profile 2 which extends the area studied in detail. The solid arrows indicate the position of the larger cracks and the dotted arrows those of the smaller cracks. The solid rectangles indicate the rock zones in the passive area, the dotted rectangles in the active area. MF: main fracture.

The active side of the profile is more fragmented as indicated by the higher density of thin cracks which is denoted by dashed arrows. Cracks are supposed to be where the Pre-P values exceed $15 \mathrm{~cm}$. The selection of this threshold value is somewhat artificial but since the area is fairly homogeneous, the designation of such a specific value can be justified. If the area were more inhomogeneous, one would have to take the local anomalies into consideration. While in the active side of the MF there are $5^{+9}$ smaller and larger cracks within the $23 \mathrm{~m}$ length (MF is not taken into consideration), in the passive side there are $6+10$ cracks $48 \mathrm{~m}$ in length. Thus while the average distance between the cracks is $1.5 \mathrm{~m}$ in the active side, it is $3 \mathrm{~m}$ on the passive side. 


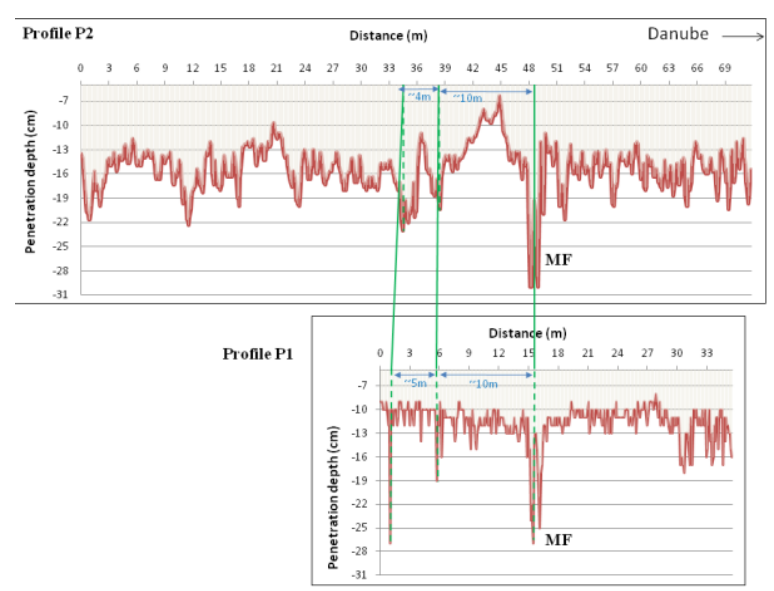

Fig. 9 The profiles which extended into the passive area. The dotted lines project the position of the anomalies to the horizontal axis. The continuous lines connect fractures observed on both profiles which are assumed to be the same. MF: main fracture.

These profile measurements thus proved the following: 1. There are cracks also in the area not yet endangered; 2 . They are at least as wide as the cracks on the active side; 3 . The passive area can be divided into blocks about twice as wide as the active area; 4 . There is lateral displacement already present in locations where is it expected ; 5 . The inner structure of the blocks is also visible inside the passive area, proving the very fine resolution of the method in spite of the former agricultural activity.

The results of the other profile, which is partly in the passive area ( $\mathrm{P}_{1}$, shown in Fig 9, where the cracks are indicated by green lines) confirm the following: 1 . There are also cracks in the passive area; 2 . The major ones of the passive area are nearly parallel to each other having about the same $10 \mathrm{~m}$ and 14-15 $\mathrm{m}$ distance from the MF on both the $\mathrm{P}_{1}$ and $\mathrm{P}_{2}$ profiles; 3. While the background Pre-P value is about $15 \mathrm{~cm}$ on profile $\mathrm{P}_{2}$, it is only $11 \mathrm{~cm}$ on profile $\mathrm{P}_{1}$. This means that the area below $\mathrm{P}_{1}$ is most likely more consolidated. 4. The anomalies of $\mathrm{P}_{1}$ are at least as large, which may nevertheless be an alert.

\section{Conclusions}

A new, extremely easy to use method, the pressure probe technique was introduced which measures a parameter proportional to the mechanical resistance of the soil. This method makes it possible to map fissure systems and to delineate loose or tight zones in areas threatened by landslides. The method thus allows a better understanding of the evolution of landslides and their delineation in appropriate circumstances when other methods might not be able to do that.

The major advantages of the method are: 1. its low cost; 2 . its relative rapidity; 3 . its almost arbitrarily high resolution power; 4 . its easy use; 5 . easy interpretation of its results; and 6. it can be used in almost any field conditions. It can be used among any topographic conditions, even in areas inaccessible by vehicles due to vegetation or landslide risk.

The main limit of the method is that it cannot be applied in areas where the mechanical properties of the soil have been exposed to artificial changes, e.g. in agricultural areas, or in areas visited by vehicles.

In spite of the noise which evidently occurs, the Pre-P method may work correctly as shown in the example that is presented. When using this method to detect the fracture system of a landslide, it is essential that the fractures reach close to the surface. Fortunately this is often the situation. The fractures are often not visible only due to vegetation cover or erosion.

If excavations are carried out simultaneously with the Pre-P field measurements at the positions where cracks are suspected, even cracks $2-3 \mathrm{~cm}$ wide can be explored and tracked. Increasing the sampling distance may lead to a loss detection of fractures, especially the thin ones. Thus, it is recommended to make the sampling distance no greater than three times the width of the expected crack. No other known methods can produce similar resolution images of the fracture system except for geotechnical ones which are, much more expensive than the Pre-P method.

The fracture system of our study area has been mapped using the Pre-P method and we concluded the following: 1. even the thinner fractures are detectable because the resolution of the measurement is very fine; 2. both the major and the minor fractures follow each other almost periodically; 3 . a well consolidated zone is attached to the fractures on the side towards the edge of the hill; 4. the fractures are often interrupted or branch out.

The results obtained measuring in the passive area showed the following: 1. cracks are present there too; 2. the cracks here are at least as wide as the cracks in the active area; 3 . the future rupture surfaces already exist; 4. in this area the blocks are about twice as wide as those in the active area.

The Pre-P enables the localisation of future rupture surfaces and the delineation of the endangered areas. In addition, it can be predicted that: 1 . near the scarp a detachment may easily occur before the slump along the MF; 2. the southern part of the study area is less endangered than the northern one (the area where profile $\mathrm{P}_{1}$ is more stable than that of the area of profile P2).

The method worked well in the study area although a part of it had been cultivated.

The Pre-P method is particularly useful for examination of landslides consisting of homogeneous rocks whose investigation is fairly limited by other 
methods. It may also be applicable for studying landslides with more heterogeneous composition but in this case less significant results can be expected.

In this article it was demonstrated that this economic method is very useful in delineation of potential landslide hazardous areas and for mapping their fracture system if the study area is not heavily influenced by human activity.

\section{Appendix A: The measuring device}

The principle of the Pre-P method using a manual pressure probe is simple: When the probe is dropped from the same height, its penetration depth depends on mechanical resistance of the soil. The probe consists of two parts: the T-shaped metal rod ( 1 in Fig. 4) and the discs superimposed on it ( 2 and 3 in Fig. 4 ) to increase its weight. There is a depth scale on the rod. The ideal drop height is $1 \mathrm{~m}$, which is convenient for most people. However, if necessary, it is possible to drop the probe from a larger height to get reasonable results in more compact soils. In such cases, increasing the weight of the probe or using a penetrometer might be simpler. For technical details of the probe see Table 1.

\section{Acknowledgments}

Sándor Szalai, one of the authors of this paper received a grant from the János Bolyai Scholarship. Great thanks to Ádám Tóth and Csaba Molnár.

\section{References}

Bányai L, Újvári G, Mentes Gy, Kovács M, Czap Z, Gribovszki K, Papp G (2014) Recurrent landsliding of a high bank at Dunaszekcső, Hungary: geodetic deformation monitoring and finite element modeling. Geomorphology, 210:1-13

Barnhardt WA, Kayen RE (2000) Radar Structure of Earthquake-Induced, Coastal Landslides in Anchorage, Alaska, Environmental Geosciences 7(1):38-45

Dikau R, Brundsen D, Schrott L, Ibsen M-L (1996) Landslide recognition: identification, movement and causes. Wiley, Chichester, UK, $274 \mathrm{p}$.

Falco P, Negro F, Szalai S, Milnes E (2013) Fracture characterisation using geoelectric null-arrays, Journal of Applied Geophysics 93:33-42

Francese R, Mazzarini F, Bistacchi A, Morelli G, Pasquarè G, Praticelli N, Robain H, Wardell N, Zaja A (2009) A structural and geophysical approach to the study of fractured aquifers in the Scansano-Magliano in Toscana Ridge, Italy, Hydrogeology Journal 17:1233-1246

Moyzes A, Scheuer Gy (1978) A dunaszekcsői magaspart mérnökgeológiai vizsgálata (Engineering geological investigation of the high bank at Dunaszekcső). Földtani Közlöny 108:213-226 (in Hungarian)
Table 1 Technical specifications of the manual pressure probe

\begin{tabular}{|c|c|}
\hline & $\begin{array}{c}\text { technical } \\
\text { specifications }\end{array}$ \\
\hline measured quantity & penetration depth in $\mathrm{cm}$ \\
\hline $\begin{array}{l}\text { maximum penetration } \\
\text { depth }\end{array}$ & $30 \mathrm{~cm}$ \\
\hline probe length and weight & $50 \mathrm{~cm}, 2.790 \mathrm{~g}$ \\
\hline $\begin{array}{l}\text { weight of the T-shaped } \\
\text { metal rod }\end{array}$ & $390 \mathrm{~g}$ \\
\hline $\begin{array}{l}\text { diameter of the metal } \\
\text { rod }\end{array}$ & $10 \mathrm{~mm}$ \\
\hline diameter of the tip end & $1,8 \mathrm{~mm}$ \\
\hline $\begin{array}{l}\text { thickness and diameter } \\
\text { of the lower weight }\end{array}$ & $20 \mathrm{~mm}, 140 \mathrm{~mm}$ \\
\hline $\begin{array}{l}\text { thickness and diameter } \\
\text { of the upper weight }\end{array}$ & $120 \mathrm{~mm}, 56 \mathrm{~mm}$ \\
\hline $\begin{array}{l}\text { recommended drop } \\
\text { height }\end{array}$ & $1 \mathrm{~m}$ \\
\hline
\end{tabular}

Szalai S, Kósa I, Nagy T, Szarka L (2009): Effectivity enhancement of azimuthal geoelectric measurements in determination of multiple directions of subsurface fissures, on basis of analogue modelling experiments, 15th European Meeting of Environmental and Engineering Geophysics, 2009, Proceedings \& Exhibitors' Catalogue Near Surface 2009, 25 pp

Szalai S, Szarka L (2008) On the classification of surface geoelectric arrays, Geophysical Prospecting 56:159-175

Taylor RW, Fleming AH (1988) Characterizing jointed systems by azimuthal resistivity surveys. Ground Water, 26:464-474

Újvári G, Mentes Gy, Bányai L, Kraft J, Gyimóthy A, Kovács J (2009) Evolution of a bank failure along the River Danube at Dunaszekcső, Hungary, Geomorphology 109:197-209

Van Westen CJ (2004) Geo-Information tools for landslide risk assessment: an overview of recent developments. In: Proc. 9th International. Symp. Landslides, Rio de Janeiro, Brazil, Balkema, Rotterdam, pp 39-56

Sándor Szalai $(\square)$

1. MTA CSFK GGI, Csatkay u. 6-8, Sopron, 9400, Hungary

E-mail: szalai@ggki.hu

Viktor Wesztergom

1. MTA CSFK GGI, Csatkay u. 6-8, Sopron, 9400, Hungary

E-mail:wv@ggki.hu

Kitti Szokoli

1. MTA CSFK GGI, Csatkay u. 6-8, Sopron, 9400, Hungary

E-mail: szk@ggki.hu 